\title{
Catch up growth and pancreatic function in growth retarded neonates
}

\author{
S P Williams, G M Durbin, M E I Morgan, I W Booth
}

\begin{abstract}
To test the hypothesis that relative pancreatic dysfunction is a determinant of catch up growth in small for gestational age (SGA) babies, 47 such babies (median gestation 38 weeks; range 27-41) and 41 appropriate for gestational age (AGA) babies matched for sex, race, and gestational age were recruited. Anthropometry was performed within 48 hours of birth and at 6 months. Faecal chymotrypsin activities were measured at 0-2 days, 14 days, 6 weeks and 6 months. At 6 months 30 SGA infants and 25 AGA infants were remeasured. In each group, median stool chymotrypsin activities doubled between 0-2 days and 6 months (9.0-25.5 IU/g SGA group; 11.6-25.3 IU/g AGA group). SGA babies had significantly lower chymotrypsin activities at 14 days $(10.9 \mathrm{U} / \mathrm{g})$ than $\mathrm{AGA}$ babies $(15 \cdot 5 \mathrm{U} / \mathrm{g})$. In the SGA group faecal chymotrypsin activities at $0-2$ days were strongly correlated with both catch up weight and with catch up length when corrected for the effects of birthweight.

These data show that impaired pancreatic exocrine function at birth is associated with severe intrauterine malnutrition and with impaired catch up growth during the first 6 months of life.

(Arch Dis Child 1995; 73: F158-F161)
\end{abstract}

Keywords: intrauterine growth retardation, pancreatic function, chymotrypsin.

Animal models of fetal malnutrition in utero have shown impaired pancreatic exocrine function in the resulting growth retarded neonate. ${ }^{1-3}$ We have recently shown that pancreatic exocrine function in humans is impaired in preterm infants who have intrauterine growth retardation (IUGR) ${ }^{4}$; evidence of depressed pancreatic exocrine function was still present at 4 weeks of age.

In some infants with IUGR catch up growth may be suboptimal. ${ }^{5}$ We therefore considered whether inadequate catch up growth could be related to relative pancreatic insufficiency. We sought an association between poor catch up growth in the first 6 months of life and early depression of pancreatic exocrine function. To perform serial, non-invasive measurements of pancreatic function we used faecal chymotrypsin as a previously validated index. ${ }^{6}$

\section{Methods}

Forty seven consecutive small for gestational age (SGA) babies, each weighing less than the third centile ${ }^{78}$ and born at Birmingham Maternity Hospital, were recruited (median gestation 38 weeks; range 27-41 weeks).

Forty two appropriate for gestational age (AGA) babies who weighed more than the 10th centile were recruited. These were the next babies born who matched the sex, race, and gestation of the previously recruited SGA babies (median gestation 39 weeks; range 29-41 weeks).

For both groups of infants, data were collected on parental occupations, marital status, smoking habits, maternal booking in weight and weight at 34 weeks' gestational age from the antenatal record. The maternal weight gain over this period was calculated. At the six month visit, parental recall of the infant's nutritional history was recorded. The differences between the groups' characteristics are summarised in table 1 .

\section{FAECAL CHYMOTRYPSIN ACTIVITY}

Single stool samples were collected from each subject at the following times: within the first 48 hours of birth, at 14 days, 6 weeks and at 6 months of age. In $87 \%$ the first sample was meconium. The samples were frozen at $-30^{\circ} \mathrm{C}$ within three days of collection and were analysed for stool chymotrypsin activity using a colorimetric method. Details of the procedure and performance data for the method have been published elsewhere. ${ }^{9}$

\section{ANTHROPOMETRY}

The following anthropometric data were collected within the first 48 hours and at 6 months: weight, length, head circumference mid arm circumference (MAC) and triceps skinfold thickness. Weight was measured on analogue scales on the labour ward by the attendant midwives. The coefficient of variation (CV) for midwife interobserver error was $0.75 \%$. All the remaining measurements were

Table 1 Differences between small for gestational age and appropriate for gestational age groups

\begin{tabular}{lccc}
\hline & $S G A$ & $A G A$ & $P<$ \\
\hline Smoking (\%) & 54 & 15 & $0 \cdot 01$ \\
Median duration of breast feeding (weeks) & 2 & 12 & $0 \cdot 05$ \\
Maternal weight gain during the first 34 & & & \\
weeks (kg) & $7 \cdot 6$ & $10 \cdot 1$ & $0 \cdot 05$ \\
Median maternal weight 34 weeks (kg) & $66 \cdot 1$ & $69 \cdot 1$ & 0.05 \\
Median maternal booking weight (kg) & $55 \cdot 6$ & $60 \cdot 6$ & $\mathrm{NS}^{\star}$ \\
Median maternal booking weight (kg) & $55 \cdot 6$ & $60 \cdot 6$ & $\mathrm{NS}^{\star}$ \\
Median social group & 3.5 & 3 & $\mathrm{NS}$ \\
Married (\%) & 65 & 76 & $\mathrm{NS}+$ \\
Non-white (\%) & 28 & 15 & $\mathrm{NS}+$
\end{tabular}

*Mann Whitney; $P>0.05$. $+\chi^{2}$ test; $P>0.05$. 


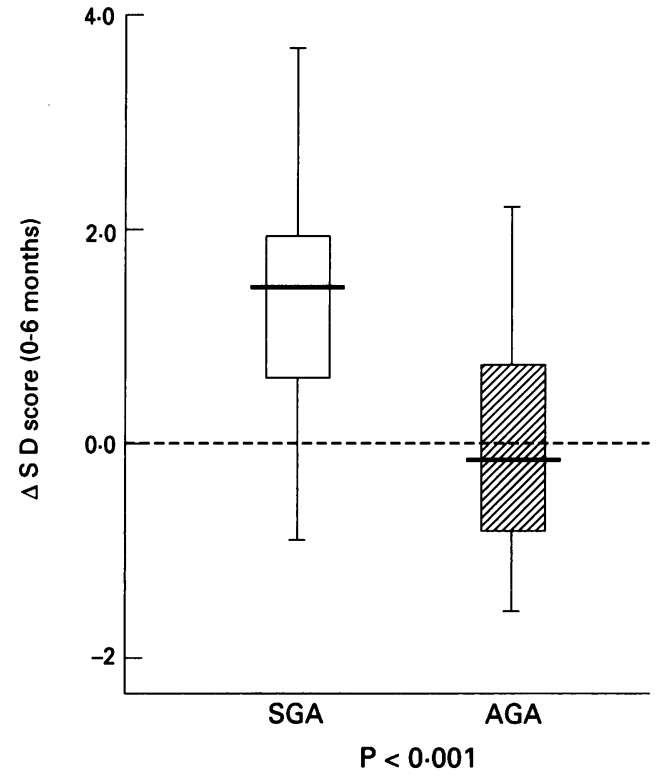

Figure 1 Relative weight gain between birth and 6 months in the $A G A$ and $S G A$ groups. The horizontal line in each box denotes the median, the limits of the box the 25 th and 75th centiles, and the bars denote the range.

made by a single researcher (SW). Weight at 6 months was measured using Seca digital scales (CV $0 \cdot 34 \%$ ). Length was measured using a Harpenden infantometer (CV $0 \cdot 62 \%$ ). Head circumference was measured at the maximum circumference using a paper tape measure $(\mathrm{CV}$ $0.86 \%$ ). The mid arm circumference was measured at the midpoint between the suprascapular spine and the tip of the olecranon (CV $2 \cdot 1 \%$ ). The triceps skinfold thickness was taken as the average of three measurements using a Holtain skin calliper taken in the same position as the mid arm circumference (CV $8 \cdot 2 \%$ ). The following variables of nutritional status were calculated: ponderal index

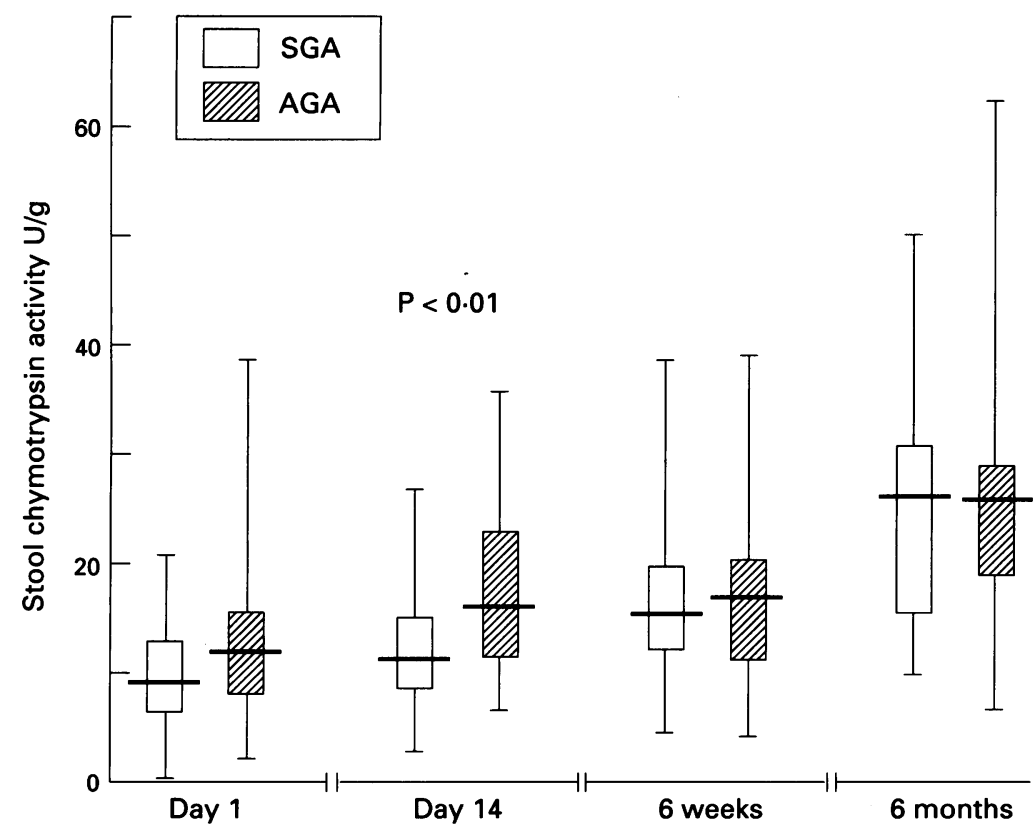

Age and birthweight group

Figure 2 Stool chymotrypsin activity by postnatal age in the SGA and $A G A$ groups. The horizontal line in each box denotes the median, the limits of the box the 25th and 75th centiles, and the bars denote the range.
Table 2 Comparison of catch up growth (change in SD score from birth to 6 months) between $S G A$ and $A G A$ groups

\begin{tabular}{llrll}
\hline & $\begin{array}{l}\text { Gestational } \\
\text { age }\end{array}$ & $\begin{array}{l}\text { Catch up } \\
\text { (SD) }\end{array}$ & $\begin{array}{l}\text { Standard } \\
\text { error }\end{array}$ & $\begin{array}{l}\text { Pvalue } \\
\text { difference }\end{array}$ \\
\hline Weight catch & SGA & 1.3 & 0.19 & $\mathrm{P}<0.0001$ \\
up & AGA & 0.0 & 0.19 & \\
$\begin{array}{l}\text { Length catch } \\
\text { up }\end{array}$ & AGA & -0.3 & 0.23 & $\mathrm{P}<0.0001$ \\
$\begin{array}{l}\text { Head } \\
\text { circumference } \\
\text { catch up }\end{array}$ & SGA & -1.4 & 0.19 & \\
\hline
\end{tabular}

(weight/length ${ }^{3}$ ), body mass index (weight/ length ${ }^{2}$ ), MAC:HC ratio and its $\mathrm{z}$-score.

\section{STATISTICAL ANALYSES}

Differences between the SGA and AGA group stool chymotrypsin activities at the various ages of collection were confirmed using the MannWhitney $U$ test. In order to compare babies born at different gestations and of different sexes the anthropometric data were converted to standard deviation scores (z-score) using the Castlemead Growth program and Gairdner Pearson data which are based on published studies. ${ }^{8}{ }^{10-12}$ Using the measurements at birth and at 6 months, catch up growth was defined as the change in $\mathrm{z}$-score for a particular variable over this period. This was calculated for weight, length, and head circumference. Differences between the two groups for catch up growth were tested using Student's $t$ test.

Within the SGA and AGA groups multiple regression analysis was used on both the anthropometric data and the stool chymotrypsin data, to identify those factors present at birth which were predictive of subsequent growth. This also allowed the effects of confounding variables to be analysed. Stool chymotrypsin activities were converted to square roots to normalise their distribution.

\section{Results}

Of the 47 SGA infants recruited, 30 attended for anthropometry at 6 months or were measured at home and therefore data are presented on these 30 subjects. Similarly, 25 of the 42 AGA infants who were recruited were measured at 6 months.

As expected the SGA group showed substantially greater catch up growth than that of the control AGA group ( $P<0 \cdot 0001$ for weight and length, $P<0.05$ for head circumference). Mean catch up weight gain in the SGA group was 1.3 standard deviations, compared with 0.0 in the control group (fig 1 and table 2). There was no association between catch up growth and duration of breast feeding.

FAECAL CHYMOTRYPSIN ACTIVITIES (fig 2)

When subject and control data were pooled, median faecal chymotrypsin activity more than doubled between birth $(10.3 \mathrm{IU} / \mathrm{g})$ and 6 months $(25.3 \mathrm{IU} / \mathrm{g})$. Activity was lower in the SGA group during the first two weeks (8.9 IU at birth, 10.9 at two weeks $v 11.6 \mathrm{IU}$ and 15.5 IU in the AGA group). This difference 
between the SGA and AGA groups became large and significant $(P<0.01)$ by 14 days when the AGA group's stool chymotrypsin activity had increased substantially from that at birth. However, at 6 weeks and 6 months, when catch up growth was occurring, there was no significant difference in chymotrypsin activity between the groups.

The most important independent predictor of catch up growth for weight in the SGA group was the stool chymotrypsin activity in the first 2 days of life $(r=0.41, P<0.05)$. The greater the chymotrypsin activity the greater the catch up growth and conversely catch up growth tended to be impaired in those whose first stool chymotrypsin activities were the lowest. The babies with the lowest birthweight standard deviation score, however, had a tendency to have both lower first 48 hour stool chymotrypsin activities and increased catch up growth. The effect of birth size on catch up growth therefore confounded the relation between catch up growth and the first stool chymotrypsin activity. When birth size was controlled for, catch up growth was even more closely related to the first $\mathbf{4 8}$ hour stool chymotrypsin activity (partial correlation; $r=0.62$; $\mathrm{P}=0.001$ for weight; $\mathrm{r}=0.38, \mathrm{P}=0.07$ for length). Multiple regression analysis showed that of the variables measured at birth, stool chymotrypsin activity was the most important independent predictor of catch up growth. Birth skinfold thickness standard deviation score was more closely correlated with catch up weight gain but was less independent of other anthropometric variables (table 3 ). The partial correlation coefficient of birth skinfold thickness and catch up weight corrected for birthweight was $-0.61, \mathrm{P}=0.002$.

Although there was a good correlation between the first 48 hours stool chymotrypsin activity and catch up growth, there was no similar correlation with subsequent stool chymotrypsin activities at 14 days, 6 weeks, and 6 months.

PREDICTORS OF RELATIVE WEIGHT GAIN OTHER THAN STOOL CHYMOTRYPSIN

The other independent predictor of the amount of catch up growth in the SGA group was skinfold thickness at birth $(r=-0.69$, $\mathbf{P}<0.001)$. There was a modest association between catch up growth and birth ponderal index in the $S G A$ group $(r=-0.36, P=0.06)$, but this was not independent of birthweight as a predictor of catch up growth. There was

Table 3 Correlation of variables recorded at birth and catch up weight gain in small for gestational age group

\begin{tabular}{|c|c|c|}
\hline \multirow[b]{2}{*}{ Variable } & \multicolumn{2}{|c|}{ Correlation } \\
\hline & $r$ Value & Pvalue \\
\hline $\begin{array}{l}0-2 \text { Day stool chymotrypsin activity (uncorrected) } \\
\text { Birthweight } \\
0-2 \text { Day stool chymotrypsin activity corrected for birthweight } \\
\text { Triceps skinfold thickness } \\
\text { Ponderal index (weight/length }{ }^{3} \text { ) } \\
\text { Body mass index (weight/length }{ }^{2} \text { ) } \\
\text { Mid arm circumference }(\text { MAC) } \\
\text { MAC: head circumference ratio } \\
\text { Average parental height z-score }\end{array}$ & $\begin{array}{r}0.41 \\
-0.40 \\
0.62 \\
-0.69 \\
-0.36 \\
-0.2 \\
-0.09 \\
-0.17 \\
0.12\end{array}$ & $\begin{array}{l}0.045 \\
0.03 \\
0.001 \\
0 \cdot 001 \\
0 \cdot 06 \\
0 \cdot 3 \\
0 \cdot 6 \\
0.4 \\
0.6\end{array}$ \\
\hline
\end{tabular}

no significant association between mode of feeding and catch up growth in the SGA group.

\section{Discussion}

We have shown that there are postnatal changes in stool chymotrypsin activity over the first 6 months of life in SGA and AGA babies. The results were consistent with intraduodenal intubation studies of protease activity ${ }^{13}$ and confirm stool chymotrypsin activity as a useful measure of pancreatic exocrine function. Stool chymotrypsin activity more than doubled over the first 6 months of life from $10 \mathrm{U}$ to $25 \mathrm{U}$ and this paralleled the results of studies of intraluminal chymotrypsin activities. ${ }^{14}$

Stool chymotrypsin activity was lower in SGA babies than in controls in the first 2 weeks but recovered by 6 weeks and remained similar to that of the AGA group at 6 months. This was consistent with a previous study of stool chymotrypsin activity which showed significantly lower stool chymotrypsin activity in SGA premature infants. However, in that group of premature babies the depression of stool chymotrypsin activity persisted for four weeks. ${ }^{4}$ Similar findings have also been made on animal models of intrauterine malnutrition $^{23}$ and early postnatal malnutrition ${ }^{1}$ where reduced concentrations of pancreatic enzymes, including proteases, have been demonstrated.

As expected, the SGA babies showed significantly greater catch up in weight than the AGA babies in the first 6 months of life. This interval was chosen on the basis of the work of Davies et $a l^{5}$ which showed that catch up in weight was most rapid in the first 6 months of life.

In SGA babies there was a strong correlation between the first 48 hour stool chymotrypsin activity and subsequent catch up growth. This was especially apparent when birthweight was controlled for. This would suggest that infants who had sustained greater intrauterine malnutrition, which was sufficiently severe to have long term sequelae on growth, had impaired pancreatic exocrine function at birth compared with infants who had less severe intrauterine conditions. An even closer correlation would have been expected if we had studied babies who had all had true intrauterine growth retardation. In fact, we would expect that within our population of SGA neonates there would have been a proportion who were small but normally nourished. The hypothesis that failure of catch up growth is causally related to pancreatic exocrine function is not supported by the data: there was no correlation between catch up growth and post-perinatal stool chymotrypsin activity in the SGA group.

Most AGA babies will have enjoyed a favourable intrauterine environment, and postnatal changes in centiles or standard deviations are therefore more likely to be attributable to postnatal than intrauterine factors. It was therefore not surprising that first day stool chymotrypsin activity was not correlated with relative weight gain in the AGA group.

There was no close correlation between 
catch up growth in either group and maternal weight at booking, at 34 weeks' gestation, or with maternal weight gain over that period.

The relation of catch up growth to the triceps skinfold thickness suggests that this may be a useful tool for a measurement of the degree of intrauterine growth retardation. Ponderal index, body mass index, and mid arm circumference, and its ratio with the head circumference, were poor predictors of catch up growth. They were no better than bodyweight $z$-score and thus their use to indicate intrauterine growth retardation in SGA and AGA infants must be questioned. ${ }^{15-18}$

These issues are of added interest because there is now increasing evidence of disturbed endocrine, as well as exocrine, pancreatic function in growth retarded infants. ${ }^{19}$ This may have important implications for carbohydrate intolerance in adult life. ${ }^{20}$ Studies at birth in IUGR infants have shown reduced insulin concentrations $^{21}$ and insulin:glucose concentration ratios. 22 Premature IUGR infants also have impaired glucose tolerance. ${ }^{23}$ In animal models of IUGR an impairment of fetal glucose transport in peripheral tissues compared with brain has been demonstrated: this may be the basis of differential organ growth in IUGR. ${ }^{22}$ There is considerable debate about the association between IUGR, weight gain in infancy, and subsequent health as an

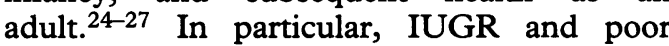
weight gain in the first year may be associated with maturity onset diabetes and mortality from ischaemic heart disease in later years. Faecal chymotrypsin activity at birth may therefore be an indicator of IUGR and be a predictor, not only of catch up growth, but also of morbidity in adult life.

We conclude that the ability of IUGR babies to show catch up growth is correlated with evidence of pancreatic exocrine function in utero, but that this is unlikely to be a causal relation.

1 Hatch TF, Lebenthal E, Krasner J, Branski D. Effect of postnatal malnutrition on pancreatic zymogen enzymes in the rat. Am 7 Clin Nutr 1979; 32: 1224-30.

2 Lebenthal E, Nitzan M, Chrzanowski BL, Krantz B. The effect of reduced maternofetal blood flow on the development of fetal pancreatic acinar cells and enzymes. Ped Res 1980; 14: 1356-9.

3 Lebenthal E, Nitzan M, Lee PC, Chrzanowski BL, Krasner J. Effect of intrauterine growth retardation on the activities of fetal intestinal enzymes in rats. Biol Neonate 1981, 39: $14-21$.
4 Kolacek S, Puntis JWL, Lloyd DR, Brown GA, Booth IW. Ontogeny of pancreatic exocrine function. Arch Dis Child 1990; 65: 178-81

5 Davies DP. Growth of small-for-dates babies. Early Hum Dev 1981; 5: 95-105.

6 Brown GA, Sule D, Williams J, Puntis JWL, Booth IW, McNeish AS. Faecal chymotrypsin: a reliable index of exocrine pancreatic function. Arch Dis Child 1988; 63: 785-9.

7 Gairdner D, Pearson J. Revised Gairdner-Pearson growth charts. Arch Dis Child 1985; 60: 1202.

8 Gairdner D, Pearson J. A growth chart for premature and other infants. Arch Dis Child 1971; 46: 783-7.

9 DelMar EG, Largman C, Broderick JW, Geokas MC. A sensitive new substrate for chymotrypsin. Analyt Biochem 1979; 99: 316 .

10 Yudkin PL, Aboualfa M, Eyre JA, Redman CWG, Wilkinson AR. New birthweight and head circumference centiles for gestational ages 24 to 42 weeks. Early Hum Dev 1987; 15: 45-52.

11 Lucas A, Cole TJ, Gandy GM. Birthweight centiles in preterm infants reappraised. Early Hum Dev 1986; 13: 313-22.

12 Keen DV, Pearse RG. Weight, length and head circumference curves for boys and girls of between 20 and 42 weeks' gestation. Early Hum Dev 1988; 63: 1170-2.

13 Boehm G, Bierbach U, Senger H, Jakobsson I, Minoli I, Moro G, et al. Activities of lipase and trypsin in duodenal juice of infants small for gestational age. $f$ Pediatr juice of infants small for gestation

14 Lebenthal E, Lee PC. Development of functional response in human exocrine pancreas. Pediatrics $1980 ; 66: 556-60$

15 Davies DP, Platts P, Pritchard JM, Wilkinson PW, Nutritional status of light for date infants at birth and its influence on early postnatal growth. Arch Dis Child 1979; 54: 703-6.

16 Kanawati AA, McLaren DS. Assessment of marginal nutrition. Nature 1970; 228: 573-5.

17 Excler JL, Sann L, Lasne Y, Picard J. Anthropometric assessment of nutritional status in newborn infants. Discriminative value of mid arm circumference and of skinfold thickness. Early Hum Dev 1985; 11: 169-78.

18 Georgieff MK, Sasanow SR, Mammel MC, Pereira GR. Mid-arm circumference/head circumference ratios for identification of symptomatic LGA, AGA, and SGA newborn infants. F Pediatr 1986; 109: 316-21.

19 Kuo PL. Glucose gradients of maternal vein-umbilical artery and umbilical vein-umbilical artery in normally artery and umbilical vein-umbilical artery in normally grown and

20 Hales CN, Barker DJ, Clark PM, Cox LJ, Fall C, Osmond $\mathrm{C}$, et al. Fetal and infant growth and impaired glucose tolerance at age 64. BMF 1991; 303: 1019-22.

21 Economides DL, Proudler A, Nicolaides KH. Plasma insulin in appropriate- and small-for-gestational-age fetuses. Am F Obstet Gynecol 1989; 160: 1091-4.

22 Simmons RA, Gounis AS, Bangalore SA, Ogata ES. Intrauterine growth retardation: fetal glucose transport is diminished in lung but spared in brain. Pediatr Res 1992; 31: 59-63.

23 Nicolini U, Hubinont C, Santolaya J, Fisk NM, Rodeck $\mathrm{CH}$. Effects of fetal intravenous glucose challenge in normal and growth retarded fetuses. Horm Metab Res 1990; 22: 426-30.

24 Lueder FL, Ogata ES. Uterine artery ligation in the maternal rat alters fetal tissue glucose. Pediatr Res 1990; 28: $464-8$.

25 Barker DJ. Fetal growth and adult disease. Br $\mathcal{f}$ Obstet Gynaecol 1992; 99: 275-6.

26 Margetts BM, Rowland MG, Foord FA, Cruddas AM Cole TJ, Barker DJ. The relation of maternal weight to the blood pressures of Gambian children. Int $\mathcal{f}$ Epidemiol 1991; 20: 938-43.

27 Barker DJ, Meade TW, Fall CH, Lee A, Osmond C, Phipps $\mathrm{K}$, et al. Relation of fetal and infant growth to plasma fibrinogen and factor VII concentrations in adult life. $B M F$ 1992; 304: 148-52.

28 Barker DJ. The fetal and infant origins of adult disease. $B M 7$ 1990; 301: 1111 . 